\title{
Hemimaxillary Enlargement, Asymmetry of the Face, Tooth Abnormalities, and Skin Findings (HATS) Syndrome: A Case Report and Review of the Literature
}

\author{
Abdullah Alakeel ${ }^{1}$ \\ 1. Dermatology, College of Medicine, King Saud University, Riyadh, SAU \\ Corresponding author: Abdullah Alakeel, dr_alakeel@hotmail.com
}

\begin{abstract}
Hemimaxillary enlargement, asymmetry of the face, tooth abnormalities, and skin findings (HATS) syndrome, a rare developmental disorder, involves the first and second branchial arches and is characterized by hemimaxillary enlargement, abnormal appearance of skin and teeth, and facial asymmetry. It is generally detected at birth or during early childhood and is associated with unilateral abnormalities of the face, including the bones, teeth, gums, and skin. Becker nevus is the most common cutaneous manifestation of HATS syndrome. Although patients with HATS syndrome have been treated with various therapeutic regimens, no standard or definitive treatment regimen has been established. This study describes this rare condition in a 12-year-old girl.
\end{abstract}

Categories: Dermatology

Keywords: hats syndrome, segmental odontomaxillary dysplasia (sod)

\section{Introduction}

Hereditary alpha tryptasemia $(\mathrm{H} \alpha \mathrm{T})$ is a genetic trait characterized by higher than normal levels of baseline serum $\alpha$-tryptase resulting from an increased number of copies of the TPSAB1 gene, which encodes $\alpha$ tryptase [1]. Individuals with higher than normal levels of baseline serum $\alpha$-tryptase (i.e., $8-10 \mathrm{ng} / \mathrm{ml}$ ) present with a multi-system disorder called hemimaxillary enlargement, asymmetry of the face, tooth abnormalities, and skin findings (HATS) syndrome, a complex disorder characterized by hemimaxillary enlargement, abnormal appearance of skin and teeth, and facial asymmetry [2,3]. Specifically, the affected portion of the face does not grow as fully as the unaffected portion. HATS syndrome is recognized by the occurrence of segmental odontomaxillary dysplasia (SOD) and hemimaxillofacial dysplasia (HD), along with unilaterally abnormalities of the skin, musculoskeletal system, gums, and teeth [4].

Received 04/20/2020 Review began 04/23/2020 Review ended 05/09/2020 Published 05/16/2020

๑) Copyright 2020 Alakeel. This is an open access article distributed under the terms of the Creative Commons Attribution License CC-BY 4.0., which permits unrestricted use, distribution, and reproduction in any medium, provided the original author and source are credited.

\section{Case Presentation}

A 12-year-old girl presented to the dermatology clinic in our institution for the evaluation of an asymptomatic hyperpigmented hairy patch over the right side of the face. This abnormality was present at birth, starting around her right eye and progressively expanding to involve the right side of her face. The patient had not experienced any developmental delays or physical problems, and there was no relevant family history of this disorder.

Physical examination showed a well-defined, light brown patch on the right side of her face with hypertrichosis (Figures $1 A, 1 B$ ), along with slight facial asymmetry. Dental examination revealed a unilateral gingival and lip hypertrophy over the right side, along with irregularly sized spaces between her teeth on her right side (Figures $2 A, 2 B$ ). Ophthalmologic examination showed that the opening of her right eye was greater than the opening of her left eye, resulting in a diagnosis of hyperopia. A biopsy of the hyperpigmented patch on her right cheek showed basal hypomelanosis with elongation of rete ridges, suggestive of Becker's nevus (Figure 3). Dental panoramic radiography showed hyperplasia of the right maxillary alveolus and basal bone with missing teeth, consisting of the upper right first and second premolars and the lower right first premolar (Figure 4). 


\section{Cureus}

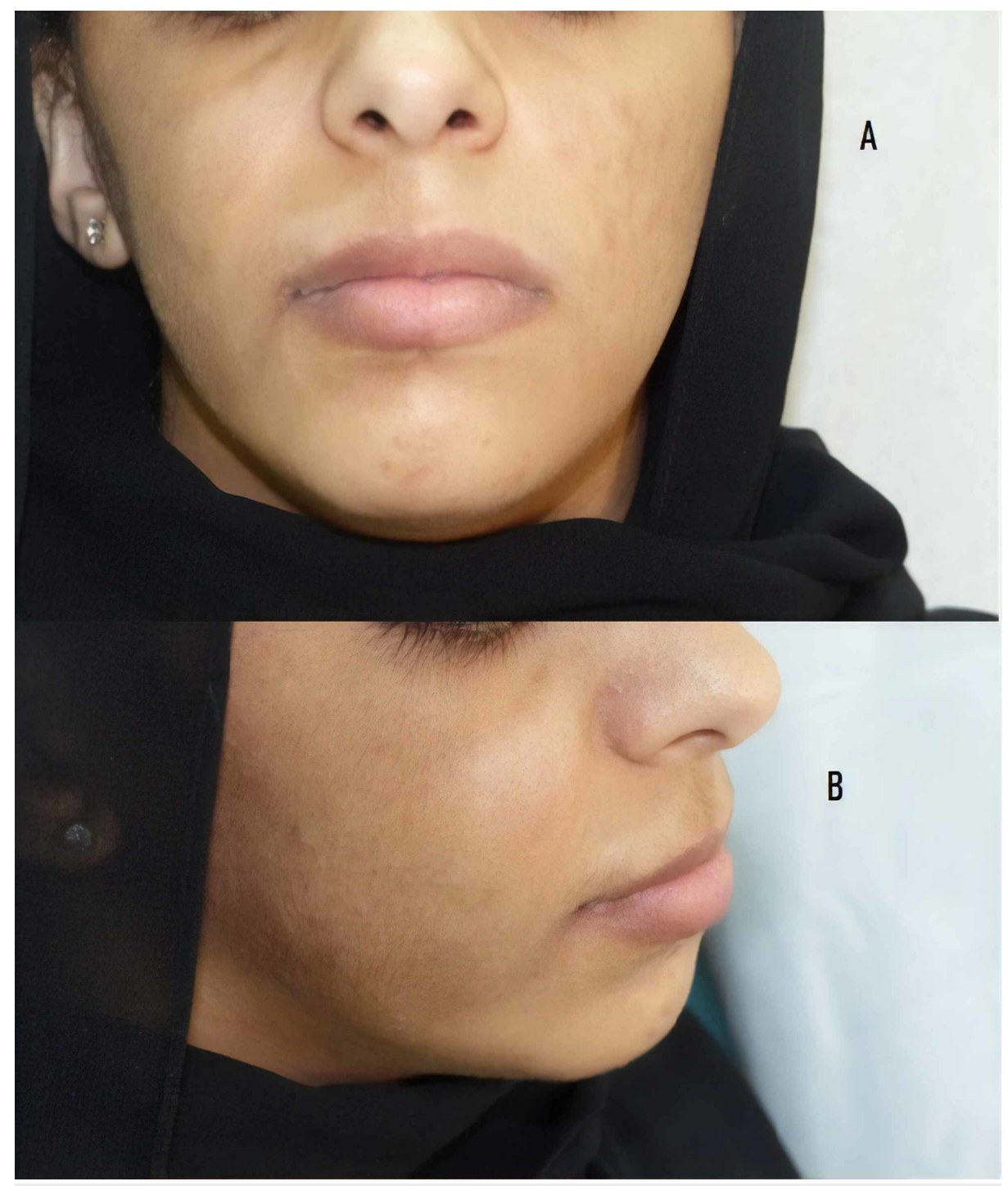

FIGURE 1: (A) Hyperpigmented hairy patch over right cheek and (B) slight lip hypertrophy over the same side. 


\section{Cureus}

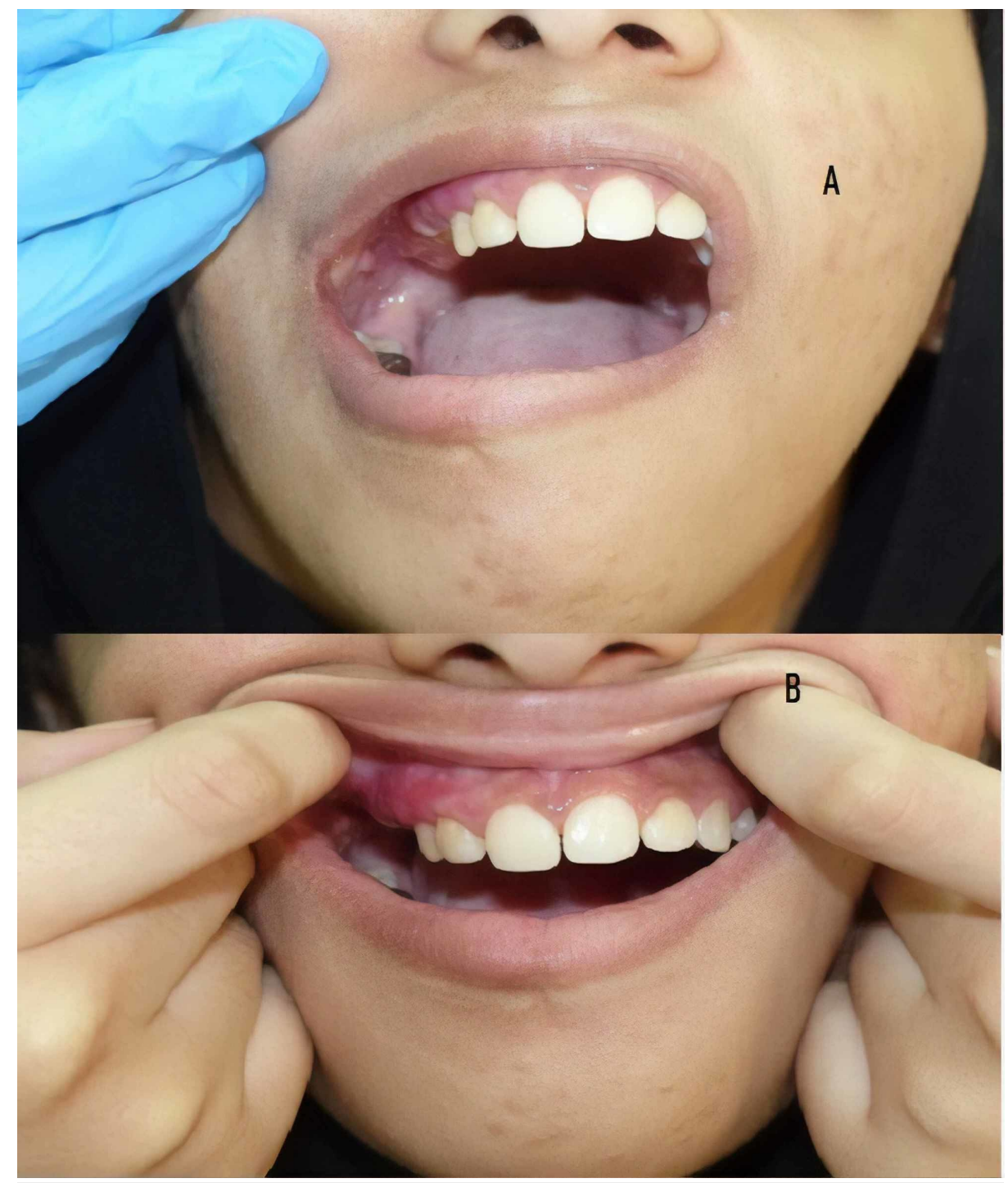

FIGURE 2: (A) Gingival hypertrophy over the right side and (B) missing and irregular spacing of the teeth on the same side. 


\section{Cureus}

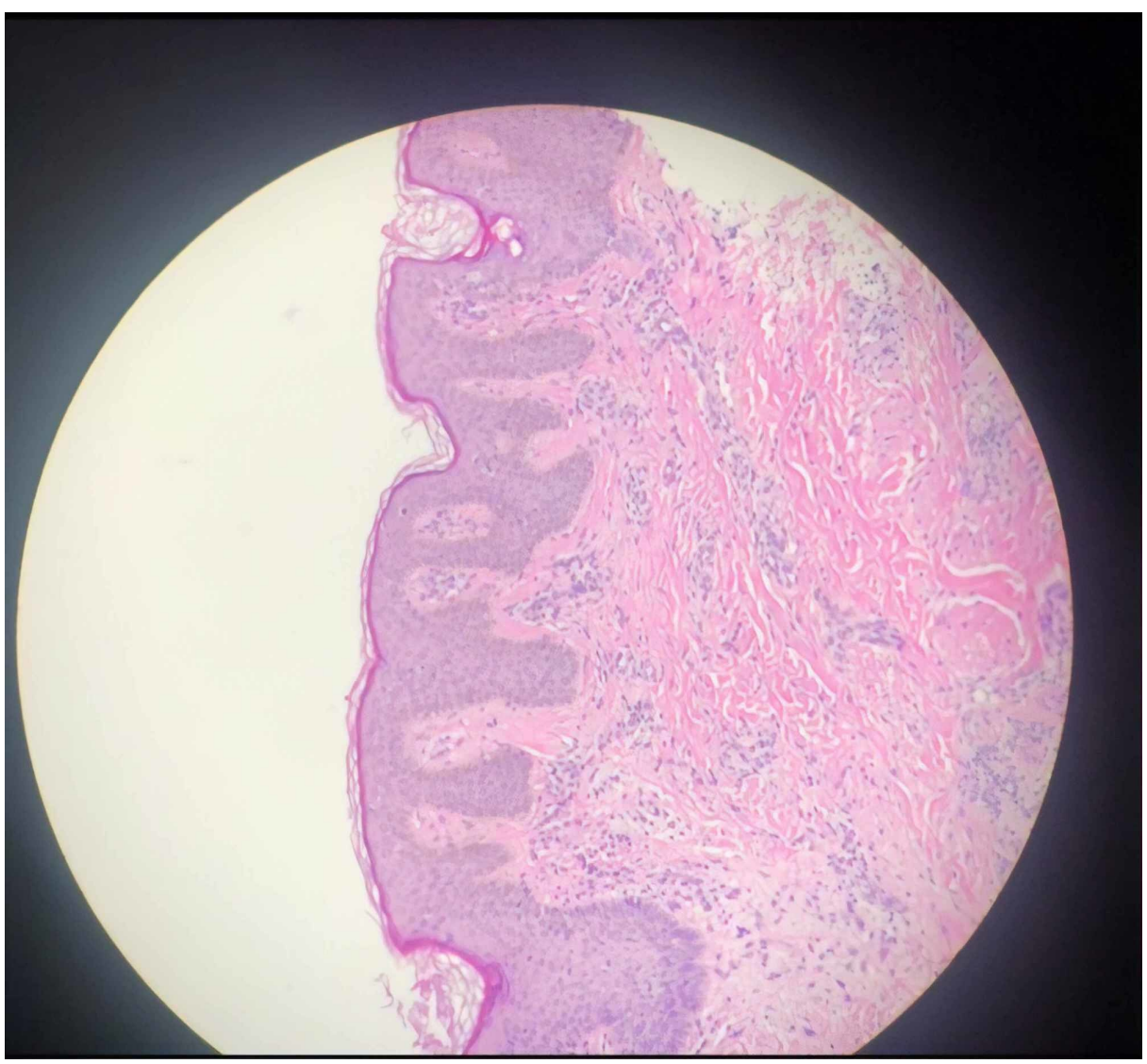

FIGURE 3: A histopathological appearance of the hyperpigmented patch on H\&E staining (high power) and hypomelanosis with elongation of rete ridges, suggestive of Becker's nevus.

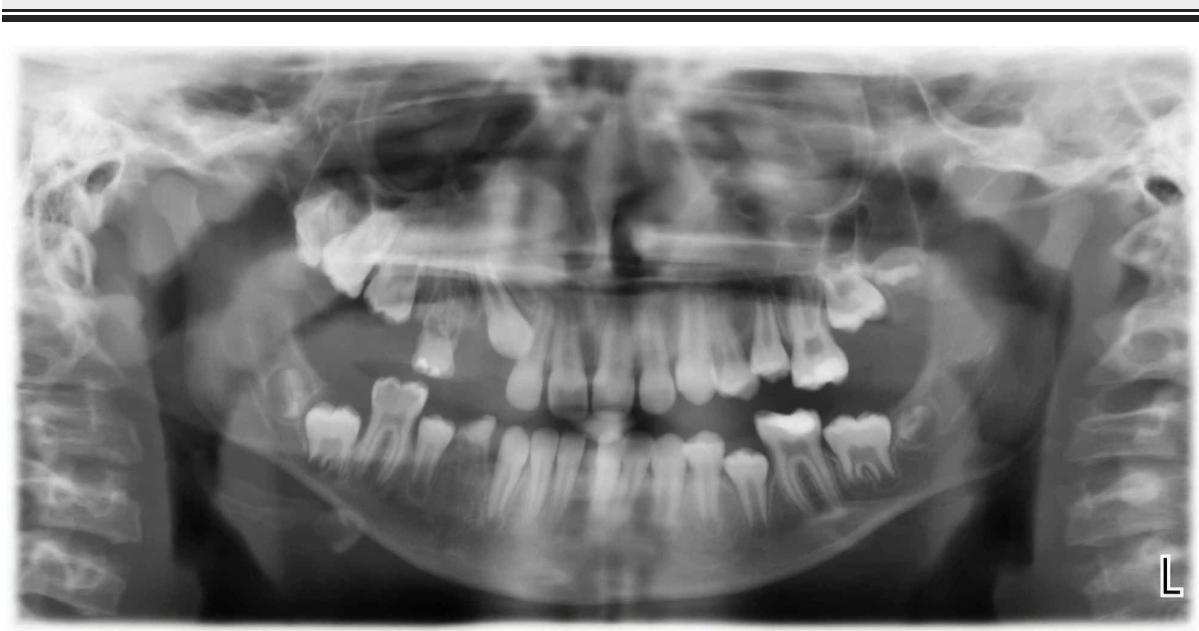

FIGURE 4: A dental radiograph demonstrating hyperplasia of the right maxillary alveolus and basal bone with missing teeth.

\section{Discussion}

HATS syndrome is considered a mental or developmental disorder usually apparent at birth or during early childhood. It is more prevalent in males than in females, with a ratio of 1.8:1.0, particularly between 2 and 28 years of age. HATS syndrome is characterized by abnormal symptoms of teeth, gums, bones, and skin, which peak during the first 10 years of life [5]. An investigation of two patients in 1987 found that one had a congenitally asymmetric face, with enlargement on one side of both maxillary gingiva and alveolar bone, and the other had hypoplastic teeth, with the affected area showing hypertrichosis [5]. The term 
hemimaxillofacial dysplasia was suggested. Eight additional patients with unilateral maxillary and gingival enlargement, dental abnormalities, and unique radiographic findings were later described as having SOD, as were patients with similar symptoms but without any changes in the skin [3,6].

Hypopigmentation of the affected part of the lip was reported in a seven-year-old girl with SOD [7]. A case series describes 12 patients with SOD, whereas other case reports described radiographic features in patients with HD or SOD $[5,8,9,10]$. The term HATS syndrome was based on findings in a patient with Becker's nevus of the skin [11]. Histopathologic findings of the teeth reported in two patients with SOD included fibrous enlargement of the pulps, an irregular pulp-dentin interface displaying many pseudo inclusions, and pulp stones [12].

In one patient with HD, maxillary dysplasia was varied, as it was due to maxillary hypoplasia rather than hyperplasia [13]. One patient with SOD presented with facial hypertrichosis, commissural lip clefting, and hyper linear palms, whereas another patient presented with unilateral ectopic eyelashes [14,15]. A 14-yearold boy with Becker's nevus presented with abnormal symptoms including an asymmetric face, hemimaxillary enlargement, and abnormal teeth, all constituents of HATS syndrome [16]. Skin manifestations can vary considerably and can include an asymmetric face, erythema, Becker's nevus or hairy nevus, hypertrichosis, hypopigmentation of the lip on the affected side, defective vermilion border, and depression [10].

The etiology of HATS syndrome remains unknown. The segmental localization of the abnormalities suggests a local developmental defect [3]. The absence of one or both premolars and early manifestations in some subjects indicate that the disturbance probably occurs in utero, at birth, or during early infancy [17]. A mutation in a progenitor cell early in embryogenesis may give rise to a genetically altered clone of cells, which later colonize or influence the morphogenesis of ectodermal and mesodermal tissues in a segment of the head and neck [18]. A similar postzygotic mutation has been observed in McCune-Albright's syndrome, resulting in genotypic and phenotypic "mosaicism" of a G protein that causes bone and skin abnormalities [19]. This type of postzygotic mutation in patients with HATS syndrome may result in genotypic mosaicism in bone and skin. Alternatively, HATS syndrome may be due to viral or bacterial infection of the maxillary branches of the trigeminal nerve (V2) [19].

Differential radiographic diagnoses include hemifacial hyperplasia, monostotic fibrous dysplasia, and regional odontodysplasia [6]. No standardized treatment modality has yet been established. Treatments to date include combined surgical and orthodontic treatment of unerupted teeth (premolars/canines), prosthodontic treatment, gingivoplasty, recontouring osteotomy for severe facial asymmetry, and reconstructive jaw surgery $[6,8]$. Becker's nevi were reported to be successfully treated with the Q-switched ruby laser, erbium:yttrium aluminum garnet laser, and 755-nm alexandrite laser [20].

\section{Conclusions}

There is a need to describe additional patients with HATS syndrome and to establish an appropriate treatment. Further genetic analysis may detect a novel causative gene in such patients.

\section{Additional Information \\ Disclosures}

Human subjects: Consent was obtained by all participants in this study. Conflicts of interest: In compliance with the ICMJE uniform disclosure form, all authors declare the following: Payment/services info: All authors have declared that no financial support was received from any organization for the submitted work. Financial relationships: All authors have declared that they have no financial relationships at present or within the previous three years with any organizations that might have an interest in the submitted work. Other relationships: All authors have declared that there are no other relationships or activities that could appear to have influenced the submitted work.

\section{References}

1. Fellinger C, Hemmer W, Wöhrl S, Sesztak-Greinecker G, Jarisch R, Wantke F: Clinical characteristics and risk profile of patients with elevated baseline serum tryptase. Allergol Immunopathol (Madr). 2014, 42:544-552. 10.1016/j.aller.2014.05.002

2. Sabato V, Chovanec J, Faber M, Milner JD, Ebo D, Lyons JJ: First identification of an inherited TPSAB1 quintuplication in a patient with clonal mast cell disease. J Clin Immunol. 2018, 38:457-459. 10.1007/s10875-018-0506-y

3. Danforth RA, Melrose RJ, Abrams AM, Handlers JP: Segmental odontomaxillary dysplasia: report of eight cases and comparison with hemimaxillofacial dysplasia. Oral Surg Oral Med Oral Pathol. 1990, 70:81-85. 10.1016/0030-4220(90)90183-s

4. Paul M, Engler D: M159 complex, persistent, multi-generational presentation of hereditary alpha tryptasemia syndrome requiring high dose omalizumab. Ann Allergy Asthma Immuno. 2019, 123:90. 10.1016/j.anai.2019.08.159

5. Miles DA, Lovas JL, Cohen MM, Jr: Hemimaxillofacial dysplasia: a newly recognized disorder of facial 
asymmetry, hypertrichosis of the facial skin, unilateral enlargement of the maxilla, and hypoplastic teeth in two patients. Oral Surg Oral Med Oral Pathol. 1987, 64:445-448. 10.1016/0030-4220(87)90150-2

6. Friedlander-Barenboim S, Kamburoğlu K, Kaffe I: Clinical and radiological presentation of hemimaxillofacial dysplasia/segmental odontomaxillary dysplasia: critical analysis and report of a case. Oral Surg Oral Med Oral Pathol Oral Radiol. 2012, 113:268-273. 10.1016/j.tripleo.2011.03.051

7. DeSalvo MS, Copete MA, Riesenberger RE, Cleveland DB, Chen SY: Segmental odontomaxillary dysplasia (hemimaxillofacial dysplasia): case report. Paediatr Dent. 1996, 18:154-156. 10.1016/j.tripleo.2011.03.051

8. Packota GV, Pharoah MJ, Petrikowski CG: Radiographic features of segmental odontomaxillary dysplasia: a study of 12 cases. Oral Surg Oral Med Oral Pathol Oral Radiol Endod. 1996, 82:577-584. 10.1016/s10792104(96)80206-X

9. Paticoff K, Marion RW, Shprintzen RJ, Shanske AL, Eisig SB: Hemimaxillofacial dysplasia: a report of two new cases and further delineation of the disorder. Oral Surg Oral Med Oral Pathol Oral Radiol Endod. 1997, 83:484-488. 10.1016/s1079-2104(97)90150-5

10. Whitt JC, Rokos JW, Dunlap CL, Barker BF: Segmental odontomaxillary dysplasia: report of a series of 5 cases with long-term follow-up. Oral Surg Oral Med Oral Pathol Oral Radiol Endod. 2011, 112:29-47. 10.1016/j.tripleo.2011.03.013

11. Welsch MJ, Stein SL: A syndrome of hemimaxillary enlargement, asymmetry of the face, tooth abnormalities, and skin findings (HATS). Pediatr Dermatol. 2004, 21:448-451. 10.1111/j.07368046.2004.21405.x

12. Armstrong C, Napier SS, Boyd RC, Gregg TA: Histopathology of the teeth in segmental odontomaxillary dysplasia: new findings. J Oral Pathol Med. 2004, 33:246-248.

13. Porwal R, Ousterhout DK, Hoffman WY, Vargervik K, Oberoi S: Hemimaxillofacial dysplasia: a variable presentation. J Craniofac Surg. 2008, 19:1554-1557. 10.1097/SCS.0b013e3181897322

14. Koenig LJ, Lynch DP, Yancey KB: Segmental odontomaxillary dysplasia presenting with facial hypertrichosis, commissural lip clefting, and hyperlinear palms. Pediatr Dermatol. 2008, 25:491-492. 10.1111/j.1525-1470.2008.00728.x

15. Bhatia SK, Drage N, Cronin AJ, Hunter ML: Segmental odontomaxillary dysplasia--a rare disorder . Eur Arch Paediatr Dent. 2008, 9:245-248. 10.1007/bf03262643

16. Alshaiji JM, Handler MZ, Huo R, Freedman A, Schachner LA: HATS syndrome: hemimaxillary enlargement, asymmetry of the face, tooth abnormalities, and skin findings. Cutis. 2014, 94:18-21.

17. Becktor KB, Reibel J, Vedel B, Kjaer I: Segmental odontomaxillary dysplasia: clinical, radiological and histological aspects of four cases. Oral Dis. 2002, 8:106-110. 10.1034/j.1601-0825.2002.1c773.x

18. Jones AC, Ford MJ: Simultaneous occurrence of segmental odontomaxillary dysplasia and Becker's nevus . J Oral Maxillofac Surg. 1999, 57:1251-1254.10.1016/s0278-2391(99)90498-6

19. Weinstein LS, Shenker A, Gejman PV, Merino MJ, Friedman E, Spiegel AM: Activating mutations of the stimulatory G protein in the McCune-Albright syndrome. N Engl J Med. 1991, 325:1688-1695. 10.1056/nejm199112123252403

20. Raulin C, Schönermark MP, Greve B, Werner S: Q-switched ruby laser treatment of tattoos and benign pigmented skin lesions: a critical review. Ann Plast Surg. 1998, 41:555-565. 10.1097/00000637-19981100000018 